\title{
Advanced soft-tissue sarcoma and treatment options: critical appraisal of trabectedin
}

REVIEW

This article was published in the following Dove Press journal:

Cancer Management and Research

17 August 2016

Number of times this article has been viewed

\author{
Ingrid M E Desar' \\ Anastasia Constantinidou ${ }^{2}$ \\ Suzanne E J Kaal' \\ Robin L Jones ${ }^{2}$ \\ Winette T A van der \\ Graaf ${ }^{\prime, 2}$ \\ 'Department of Medical Oncology, \\ Radboud University Medical Center, \\ Nijmegen, the Netherlands; ${ }^{2}$ The \\ Institute of Cancer Research and the \\ Royal Marsden NHS Foundation Trust, \\ London, UK
}

\begin{abstract}
Soft-tissue sarcomas (STS) are a heterogeneous group of rare solid tumors of mesenchymal origin. This paper reviews the current status of systemic treatment in advanced and metastatic soft tissue sarcomas, with an emphasis on trabectedin. Trabectedin is a unique type of chemotherapeutic agent with multiple potential mechanisms of action. We discuss the putative mechanisms, as well as the toxicity and administration schedules of trabectedin, followed by its efficacy in first-line systemic therapy and beyond first-line systemic therapy.
\end{abstract}

Keywords: soft-tissue sarcoma, trabectedin, chemotherapy

\section{Introduction}

Soft-tissue sarcomas (STS) are a heterogeneous group of rare solid tumors of mesenchymal origin. STS account for approximately $1 \%$ of adult cancers, with an annual incidence of 5 per 100,000 inhabitants. ${ }^{1}$ Although STS can arise anywhere in the body, the majority occur in the limb or limb girdle $(60 \%)$ or within the abdomen (retroperitoneal and intraperitoneal, 20\%). ${ }^{2}$ Over 50 different subtypes of STS have been identified in the latest World Health Organization classification of tumors of soft tissue and bone based on clinical insights, histopathology, and molecular biology. ${ }^{3}$ The most common subtypes, together accounting for about three-quarters of all STS, are undifferentiated pleomorphic sarcoma, liposarcoma, leiomyosarcoma, myxofibrosarcoma, synovial sarcoma, and malignant peripheral nerve sheath tumors. ${ }^{3}$ Molecular diagnostics are increasingly used to identify histological subtypes of STS. ${ }^{4}$ The etiology of most STS is unknown, but in a minority of STS patients an association exists with irradiation, ${ }^{5,6}$ chronic lymphangioedema, ${ }^{7}$ viral infections (eg, HHV-8 in Kaposi sarcoma), ${ }^{8}$ and known genetic susceptibility (eg, malignant peripheral nerve sheath tumors in neurofibromatosis type). ${ }^{9}$ About $10 \%$ of patients have detectable metastases (most common in the lungs) at diagnosis of the primary tumor and, depending on the grade, overall, one-third to half of patients with STS die due to tumor-related diseases. ${ }^{3}$

In this review, we focus on the currently available systemic treatment strategies for advanced or metastatic STS in adults, with an emphasis on trabectedin.

\section{Current standard of care for advanced STS: in a glance}

Localized STS have traditionally been managed by wide excisional surgery with or without radiotherapy. The use of chemotherapy or targeted therapy has mostly been
15 Cotswold Road, Sutton,

London SM2 5NG, UK

Email Winette.vanderGraaf@icr.ac.uk 
reserved for advanced disease, aiming to achieve disease palliation and control. The profound heterogeneity of STS subtypes complicates the conduct and interpretation of clinical trials. Within the group of STS, subtypes have been identified as less or more sensitive to systemic therapy, but most studies recruit all histological subtypes and are not powered for this kind of subgroup analyses. Therefore, most STS subtypes are treated in the same way. Selected sarcomas, including gastrointestinal stromal tumors (GIST), Ewing family of tumors, and embryonal or alveolar rhabdomyosarcomas, are exceptions that are effectively treated with specific systemic therapies and are excluded from this review. ${ }^{10}$

Cytotoxic chemotherapy is the mainstay of therapy for advanced or metastatic STS (Table 1). Targeted therapy, in particular pazopanib, ${ }^{11}$ currently has a modest role but is under extensive investigation and is likely to gain further importance in advanced STS. A number of early trials utilizing immunotherapy have been initiated. A recent review summarizes gold standard and novel therapies for advanced STS. ${ }^{12,13}$

\section{First-line systemic therapy \\ Doxorubicin or combination of doxorubicin plus ifosfamide}

The anthracycline doxorubicin is considered to be the standard first-line systemic therapy for advanced STS. ${ }^{10,12}$ Doxorubicin is administered intravenously (IV) at a dose of 60-75 mg/ $\mathrm{m}^{2}$ every 3 weeks. This drug has dose-limiting cumulative cardiotoxicity. Response rates for single-agent treatment with doxorubicin vary between $16 \%$ and $27 \%$. Median overall survival (OS) varies between 7.7 and 12 months. ${ }^{14}$ In 2003, a Cochrane review based on eight randomized controlled trials compared doxorubicin as single agent to doxorubicin-based combination therapy (of which two trials were with doxorubicin and ifosfamide). For the combination schedules, a response rate varying between $14 \%$ and $34 \%$ was found with a median OS of 7.3-12.7 months. It was concluded that doxorubicin-based combinations add a marginal increase in response rate, at the expense of increased toxic effects, but no significant improvement in OS. ${ }^{14}$ In 2014, the EORTC STSBG 62012 study compared single-agent doxorubicin to the combination of doxorubicin and ifosfamide with comparable results: a response rate of $13.6 \%$ vs $26.5 \%$, median progression-free survival (PFS) of 4.6 vs 7.4 months, and no significant difference in median OS (12.8 vs 14.3 months) but significantly more adverse events in the combination arm. ${ }^{15}$ Therefore, the combination of doxorubicin and ifosfamide is recommended when a volume response is the primary aim, eg, in cases of symptomatic disease (pain and dysfunction) or induction treatment before radical surgery.

A Phase III trial randomizing patients with advanced/ metastatic STS to receive first-line therapy with either doxorubicin + palifosfamide or doxorubicin + placebo reported no difference in PFS and OS between the two arms. Furthermore, another Phase III trial randomizing patients to receive doxorubicin + evofosfamide or single-agent doxorubicin also reported no difference in outcome (NCT01440088). Therefore, on the basis of the results of these Phase III trials, single-agent doxorubicin is generally regarded as standard first-line therapy for patients with advanced/metastatic STS.

Currently, the combination of doxorubicin and the platelet-derived growth factor receptor alpha antibody olaratumab is under investigation as first-line treatment for all STS subtypes. In the Phase II study, up to eight cycles of

Table I Systemic therapies for advanced or metastatic STS, other than trabectedin

\begin{tabular}{|c|c|c|c|c|c|}
\hline Drug & Reference & ORR (\%) & $\begin{array}{l}\text { mPFS } \\
\text { (months) }\end{array}$ & $\begin{array}{l}\text { mOS } \\
\text { (months) }\end{array}$ & Most commonly reported adverse events \\
\hline Doxorubicin & 14 & $16-27$ & 4.6 & $7.7-12.8$ & Leucopenia, neutropenia \\
\hline Doxorubicin + ifosfamide & 15 & $14-34$ & 7.4 & $7.3-14.3$ & $\begin{array}{l}\text { Leucopenia, neutropenia, febrile neutropenia, anemia, } \\
\text { thrombocytopenia, nausea, vomiting, encephalopathy }\end{array}$ \\
\hline Gemcitabine + docetaxe $^{a}$ & $|7-2|$ & $5-52$ & $6-6.2$ & $16-26.9$ & $\begin{array}{l}\text { Anemia, fatigue, alopecia, thrombocytopenia, dyspnea, } \\
\text { neutropenia }\end{array}$ \\
\hline Taxanes $^{b}$ & $22-27$ & $7-89$ & - & $7-9.5$ & Anemia, neutropenia, fatigue, neuropathy \\
\hline Cyclophosphamide + prednisone & 29 & 26.9 & 6.8 & - & Lymphopenia, anemia, thrombocytopenia \\
\hline Ifosfamide & $30-34$ & $20-25$ & - & 12 & Fatigue, nausea, vomiting \\
\hline Gemcitabine & $35-39$ & $3.2-27$ & $1.5-6.3$ & $7.2-20$ & Hematologic toxicities, increased ALT levels, myalgia, rash \\
\hline Dacarbazine & $40-44$ & $4-18$ & 2 & $8.2-11.5$ & Hematologic toxicities, fatigue, nausea vomiting, stomatitis \\
\hline Eribulinc & 44 & 4 & 2.6 & 13.5 & $\begin{array}{l}\text { Fatigue, nausea, alopecia, constipation, leukopenia, } \\
\text { neutropenia, anemia }\end{array}$ \\
\hline Pazopanib & 11 & 6 & 4.6 & 12.5 & Fatigue, diarrhea, nausea, weight loss, hypertension \\
\hline
\end{tabular}

Notes: an (mainly uterine) leiomyosarcoma, bin angiosarcoma, in leiomyosaroma and liposarcoma.

Abbreviations: STS, soft tissue sarcoma; ORR, objective response rate; mPFS, median progression free survival; mOS, median overall survival; ALT, alanine aminotransferase. 
doxorubicin ( $75 \mathrm{mg} / \mathrm{m}^{2}$ every 3 weeks) were combined with olaratumab $15 \mathrm{mg} / \mathrm{kg}$ IV day 1 and 8 for every 3 weeks. ${ }^{16}$ Interim OS analysis showed an impressive difference of 25.0 vs 14.7 months (hazard ratio $[\mathrm{HR}]=0.44, P=0.0005$ ) in favor of the combination therapy. There was no significant difference in objective response rate (ORR), 18.8\% and 12.3\%, respectively, for the combination and single-agent arms. The Phase III study has nearly completed enrollment.

\section{Gemcitabine-docetaxel}

In patients with metastastic leiomyosarcoma, especially uterine leiomyosarcoma, the combination of fixed-dose gemcitabine (900 mg/m² IV day 1 and 8q21 days) with docetaxel (100 mg/ $\mathrm{m}^{2}$ IV day $8 \mathrm{q} 21$ days) is used based on three Phase II studies in patients with advanced or metastatic leiomyosarcoma. ${ }^{17-19}$ For patients with uterine leiomyosarcoma, response rates ranged between $24 \%$ and $52 \%$. However, the best response rate in patients with nonuterine leiomyosarcoma was only $5 \%$. Recently, a Phase III study was published comparing gemcitabine and docetaxel plus bevacizumab vs gemcitabine and docetaxel plus placebo as first line in 107 patients with uterine leiomyosarcoma. No differences between the two study arms were reported. Response rates were $35.8 \%$ and $31.5 \%$, median PFS was 4.2 and 6.2 months, and median OS was 23.3 and 26.9 months for the placebo vs the bevacizumab arm, respectively. ${ }^{20}$ The results of the UK GeDDIS trial have been presented at the ASCO annual meeting in 2015. In this Phase III trial, 257 patients with STS were randomized between doxorubicin $75 \mathrm{mg} / \mathrm{m}^{2} \mathrm{q} 21$ days or the combination of gemcitabine $650 \mathrm{mg} /$ $\mathrm{m}^{2}$ day 1 and $8 \mathrm{q} 21$ days and docetaxel $75 \mathrm{mg} / \mathrm{m}^{2}$ every 21 days. No significant difference in median PFS (23 and 24 weeks, respectively) or median OS (71 and 63 weeks, respectively) was reported. Subgroup analysis showed no benefit for patients with leiomyosarcoma treated with gemcitabine-docetaxel compared to other histological subtypes. The full paper is not yet published. ${ }^{21} \mathrm{~A}$ Phase II trial is currently recruiting and randomizing patients with advanced/metastatic leiomyosarcoma to trabectedin or gemcitabine-docetaxel (NCT02249702).

\section{Taxanes}

In patients with advanced or metastatic angiosarcoma, taxanes have shown efficacy, based on the results of several retrospective studies and Phase II trials. These include paclitaxel in a weekly or 3-weekly schedule and docetaxel in a 3-weekly schedule. ${ }^{22-27}$ Response rates vary between $7 \%$ and $89 \%$ (best response rates in facial and scalp angiosarcoma) and median OS between 7 and 9.5 months. ${ }^{22-27}$ A recent Phase II study combining paclitaxel with bevacizumab vs single-agent paclitaxel in angiosarcoma did not show a benefit for the combination. ${ }^{28}$

\section{Metronomic cyclophosphamide and prednisolone}

In elderly frail patients with advanced or metastatic STS, unfit for standard first-line therapy with doxorubicin or combination of doxorubicin and ifosfamide, the combination of oral cyclophosphamide $100 \mathrm{mg}$ twice daily and prednisolone 20 mg daily from day 1 to 7 every 14 days has been reported to show benefit. In a retrospective study performed at the Institut Gustave Roussy, the response rate was $26.9 \%$, disease control rate was $69.2 \%$, and median PFS was 6.8 months. ${ }^{29}$ Further studies are required to define the precise role of this schedule in patients with advanced/metastatic STS. Lymphopenia, anemia, and thrombocytopenia were the most common reported adverse events.

\section{Beyond first line of systemic therapy}

After failure to first-line therapy, several systemic options are available, and the selection of a specific schedule is made on the basis of individual patient-based considerations, including expected toxicity, tumor burden, and histological subtype. In a recent review by the Royal Marsden Hospital Sarcoma Unit, a proposal for sequencing therapy was published. ${ }^{12}$

\section{Ifosfamide}

As a monotherapy, the alkylating agent ifosfamide has activity varying from $4.8 \%$ to $62.5 \%{ }^{30}$ In subsequent studies, ifosfamide consistently yielded response rates of approximately $20 \%-25 \%$ in the metastatic setting, with a median OS duration of 1 year, results comparable to those obtained with doxorubicin. ${ }^{31}$ Several doses and schedules of ifosfamide have been investigated in STS patients. There is a clear dose-response relationship with this agent, and consequently higher doses up to $12-18 \mathrm{~g} / \mathrm{m}^{2}$ and prolonged dosing schedules have been studied. Dose-limiting toxicities are bone marrow suppression, hemorrhagic cystitis, and encephalopathy. A randomized trial comparing two different schedules of ifosfamide $9 \mathrm{~g} / \mathrm{m}^{2}$ to doxorubicin demonstrated no advantage for ifosfamide over doxorubicin. ${ }^{32}$ In a large retrospective analysis of the EORTC Soft Tissue and Bone Sarcoma Group, synovial sarcomas showed a higher response rate on ifosfamide-containing regimens than on doxorubicin. ${ }^{33}$ Prolonged infusion of ifosfamide $\left(1 \mathrm{~g} / \mathrm{m}^{2} / \mathrm{d}\right.$ for 14 days in cycles of 28 days) has retrospectively been reported in 35 STS patients with encouraging results. Partial response was seen in $20 \%$ of the patients, and stable disease in another $29 \%$. In the subgroup with dedifferentiated liposarcoma 
$(n=22)$, the partial response rate was $22.7 \%$ and stable disease in $31.8 \%$. Median PFS and OS were 4.2 and 11.2 months, respectively. The most common toxicities were fatigue, nausea, and vomiting. ${ }^{34}$

\section{Gemcitabine}

Gemcitabine is an antimetabolite of pyrimidine. In unselected STS, a weekly gemcitabine schedule with 1,000-1,250 mg/ $\mathrm{m}^{2}$ administered in 30 minutes with a pause week every 3-4 weeks is most frequently used. In six gemcitabine monotherapy Phase II studies with pretreated unselected STS, ORRs of $3.2 \%-27 \%$ were reported. Median PFS varied between 1.5 and 6.3 months and median OS between 7.2 and 20 months. ${ }^{19,35-39}$ Most frequently occurring toxicities are hematologic toxicities, increased alanine aminotransferase levels, myalgia, and rash.

\section{Dacarbazine}

Dacarbazine is an alkylating agent and is administered $1.2 \mathrm{~g} / \mathrm{m}^{2}$ every 3 weeks IV as a monotherapy. In three secondline Phase II trials, the response rate was $4 \%-18 \%$, with a median PFS of 2 months and a median OS of 8.2 months. ${ }^{40-42}$ Most reported toxicities are hematologic toxicities, nausea, vomiting, flulike symptoms, and diarrhea. ${ }^{40}$

Recently, dacarbazine was the standard arm in comparison to trabectedin in a large Phase III study for patients with metastatic liposarcoma or leiomyosarcomas after failure of conventional chemotherapy. The dacarbazine group had a median PFS of 1.5 months and a median OS of 12.9 months. ${ }^{43}$ This trial is discussed in more detail in the "Trabectedin" section.

Dacarbazine (500 mg/m² q2weeks) has been combined with gemcitabine $\left(1,800 \mathrm{mg} / \mathrm{m}^{2} \mathrm{q} 2\right.$ weeks $)$ in two Phase II trials, of which one randomized against single-agent dacarbazine. ${ }^{41,42}$ For the combination, median PFS was 4.2 months and median OS 16.8 months in the randomized Phase II trial. Despite hematologic toxicities, fatigue, nausea, vomiting, and stomatitis were the most reported adverse events.

\section{Eribulin}

Recently, the results of a Phase III trial comparing eribulin to dacarbazine were published. ${ }^{44} \mathrm{~A}$ total of 452 patients with intermediate- or high-grade advanced liposarcoma or leiomyosarcoma who had received at least two previous systemic regimens for advanced disease (including an anthracycline) were randomized $1: 1$ to eribulin mesilate $\left(1.4 \mathrm{mg} / \mathrm{m}^{2} \mathrm{IV}\right.$ on days 1 and 8 ) or dacarbazine (850-1,200 mg/m² IV on day 1) every 21 days until disease progression. OS was significantly improved in patients assigned to eribulin compared with those assigned to dacarbazine (median OS $=13.5$ vs 11.5 months; $\mathrm{HR}=0.77$ ). This OS benefit was only seen in liposarcoma patients (median OS $=15.6$ vs 8.4 months, respectively) and not in those with leiomyosarcoma (12.7 vs 13.0 months). However, this study was not powered for such subgroup analyses. Median PFS was similar in both treatment groups: 2.6 months. Most reported adverse events for eribulin were fatigue, nausea, alopecia, constipation, leukopenia, neutropenia, and anemia.

\section{Pazopanib}

Currently, the tyrosine kinase inhibitor pazopanib is the only targeted therapy approved for advanced or metastatic nonadipocytic, non-GIST STS after failure of standard chemotherapy. Pazopanib has activity against VEGFR1-2, PDGFR A-B, and KIT. In the PALETTE study, ${ }^{11} 369$ patients were randomized 2:1 to receive pazopanib $800 \mathrm{mg}$ once daily orally or placebo. Median PFS was significantly longer in the pazopanib arm, 4.6 vs 1.6 months $(\mathrm{HR}=0.31,95 \%$ $\mathrm{CI}=0.24-0.40, P<0.0001)$, but no significant difference in median OS was found (12.5 vs 10.7 months, HR $=0.85,95 \%$ $\mathrm{CI}=0.67-1.11, P=0.25$ ). Partial responses were seen in $6 \%$ of the patients on pazopanib, and another $67 \%$ had stable disease as best response. Most reported adverse events were fatigue, diarrhea, nausea, weight loss, and hypertension. Quality of life did not differ between both arms but was only monitored during the first 12 weeks of treatment.

\section{Trabectedin: pharmacology, mode of action, pharmocokinetics, toxicity, and registration}

Trabectedin (Yondelis ${ }^{\circledR}$, Janssen Biotech, Inc, Horsham, PA, USA) is a tetrahydroisoquinoline, which was originally isolated from the Caribbean tunicate Ecteinascida turbinata and is currently produced synthetically. ${ }^{45}$

Trabectedin has several modes of action. Unlike classical alkylating chemotherapeutic drugs, which bind to the major DNA groove, trabectedin binds to specific selected triplets of the DNA minor groove. This results in a distortion of the double helix structure and causes double-strand breaks, leading to tumor cell apoptosis. Part of the molecule protrudes out of the DNA and interacts with proteins at the site of the adduct, such as XPG and RNA polymerase II (Pol II). This results in inhibition of transactivated transcription in a nucleotide excision repair-dependent manner. ${ }^{46,47}$ This impact on transcription is especially of interest in translocation-related sarcomas, such as myxoid liposarcoma 
and Ewing sarcoma. In myxoid liposarcomas, the presence of $t(12 ; 16)$ or $t(12 ; 22)$ translocations leads to FUS-CHOP or EWS-CHOP fusion proteins. Trabectedin displaces these fusion proteins from its target promoters, resulting in the differentiation of myxoid liposarcoma cells into normal adipocytes. ${ }^{48}$ In Ewing sarcoma, the translocation $t(11 ; 22)$ results in an oncogenic fusion gene EWS-FLI1, a crucial driver for the oncogenic transformation and survival of Ewing sarcoma cells. Trabectedin has a specific inhibitory effect on the aberrant transcriptional activity of this oncogenic chimera, thereby reversing the gene signature of induced downstream targets of EWS-FLII and inducing apoptosis. ${ }^{49,50}$

Apart from these molecular mechanisms, trabectedin also influences the tumor microenvironment. Trabectedin induces rapid apoptosis exclusively in mononuclear phagocytes (macrophages and monocytes), with a subsequent strong decrease in the production of several cytokines and chemokines such as IL-6, CCL2, CXCL8, Angiopoietin 2, and VEGF. This results not only in diminished tumor growth, but also in inhibition of tumor angiogenesis and modulation of stroma-mediated resistance to therapy. ${ }^{46}$

Trabectedin is administered IV. The approved schedule is a 24-hour supply using a central venous catheter. Shorter schedules (eg, 1 or 3 hours) have been tested, but have not shown benefit. ${ }^{51-53}$ Trabectedin has a high volume of distribution since $94 \%-98 \%$ of trabectedin within the plasma is bound to albumin. Trabectedin is metabolized by the cytochrome P450 system, especially CYP3A4. Less than 1\% is eliminated unchanged in the urine. The terminal half-life time is long, approximately 180 hours. A population pharmacokinetic analysis indicated that the plasma clearance of trabectedin is not influenced by age, sex, total body weight, or body surface area. There are no data available in patients with a creatinine clearance below $30 \mathrm{~mL} / \mathrm{min}$. The mode of metabolism and elimination suggest no significant impact of decreased renal function. The impact of hepatic failure on trabectedin pharmacokinetics is unclear, but because of its toxicity profile with (sometimes) highly elevated hepatic enzyme levels, caution is warranted. ${ }^{54}$

The most common adverse events of trabectedin are neutropenia ( $50 \% \geq$ grade 3$)$, thrombocytopenia ( $13 \% \geq$ grade 3 ), anemia (13\% $\geq$ grade 3$)$, anorexia, nausea, vomiting, diarrhea or constipation, fatigue, asthenia, hyperbilirubinaemia (1\% grade $3)$, and elevated ALT ( $41 \% \geq$ grade 3$)$ or aspartate aminotransferase (AST) $(51 \% \geq$ grade 3$)$, or creatinine phosphokinase (4\% $\geq$ grade 3$).{ }^{54}$ Trabectedin is administered until progressive disease or intolerability. Recently, a randomized Phase II study was reported, which compared interruption of trabectedin after six cycles in patients with responding or stable disease to continuation of trabectedin and found a worse PFS in the discontinuation group (PFS at 6 months after randomization $23.1 \%$ vs $51.9 \%$, respectively). ${ }^{55}$

In Europe, trabectedin is approved by European Medicines Agency for advanced STS after failure of anthracyclines. In the United States, the US Food and Drug Administration approved trabectedin in November 2015 for the treatment of patients with unresectable or metastatic liposarcoma or leiomyosarcoma previously treated with an anthracyclinecontaining regimen, on the basis of the randomized trial comparing dacarbazine to trabectedin. ${ }^{43}$ Furthermore, it is registered for relapsed ovarian cancer in combination with pegylated liposomal doxorubicin.

\section{Trabectedin in sarcoma: efficacy Efficacy in first line}

In three Phase II/IIb trabectedin studies in chemotherapy naïve unselected STS patients, response rates were moderate (10\%-17.1\%) and median PFS was short (1.6-5.8 months). Median OS data are not yet available (Table 2). ${ }^{52,56,57}$ In the TRUSTS study, a direct comparison with doxorubicin was made. ${ }^{52}$ There were no significant differences in ORR, median PFS, or median OS. As already mentioned, response rates for single-agent treatment with doxorubicin vary between $16 \%$ and 27\%. Median OS varies between 7.7 and 12 months. ${ }^{14}$ Taken together, in unselected advanced or metastatic STS, there is no evidence to choose trabectedin above the regular standard first-line therapy with doxorubicin.

A Phase III trial in 121 translocation-related sarcomas did not show any superiority for either doxorubicin or trabectedin in a direct comparison between those two drugs. ${ }^{58}$ Again, ORRs were numerically higher in doxorubicin-treated patients $(27 \%$ vs $5.9 \%)$, although this was not statistically significant.

\section{Beyond first-line systemic treatment}

In four Phase II trials in unselected, pretreated, STS patients, the reported response rates were $2.8 \%-8 \%$, median PFS was 1.7-3.5 months, and median OS was 9.2-12.8 months for trabectedin. ${ }^{59-62}$

A randomized Phase II study comparing trabectedin to best supportive care in translocation-related sarcomas showed a significantly better response rate ( $8 \%$ vs $0 \%)$, longer median PFS (5.6 vs 0.9 months, HR $=0.07$ ), and longer median OS (not reached vs 8 months, HR $=0.42$ ). ${ }^{63}$ A large Phase II study in 270 patients with liposarcoma or leiomyosarcoma compared two different trabectedin schedules. Again, low 
Table 2 Results of trabectedin trials in STS patients

\begin{tabular}{|c|c|c|c|c|c|c|c|}
\hline Reference & Phase & Design & $\mathbf{n}$ & RR (\%) & $\begin{array}{l}\text { TTP } \\
\text { (months) }\end{array}$ & PFS (months) & OS (months) \\
\hline 70 & 1 & $\begin{array}{l}\text { Japanese STS pts, after } \\
\text { failure of anthracyclines, } \\
\text { dose escalation, MTD } \\
1.2 \mathrm{mg} / \mathrm{m}^{2} \mathrm{q} 2 \mathrm{I} \text { day }\end{array}$ & 15 & 20 & NA & NA & NA \\
\hline 56 & II & $\begin{array}{l}\text { TRB } 1.5 \mathrm{mg} / \mathrm{m}^{2} 24 \mathrm{hq} 2 \mathrm{I} \\
\text { STS first-line STS }\end{array}$ & 35 & 17.1 & - & 1.6 & 15.8 \\
\hline 57 & II & $\begin{array}{l}\text { TRB I. } .5 \mathrm{mg} / \mathrm{m}^{2} \mathrm{q} 2 \mathrm{Id} \text {, } \\
\text { u-LMS, first-line STS }\end{array}$ & 20 & 10 & 4.5 & 5.8 & $\begin{array}{l}>26.1 \text { (median not } \\
\text { reached) }\end{array}$ \\
\hline 52 & Ilb & $\begin{array}{l}\text { Doxo vs TRB } 3 \text { vs TRB } \\
24 \text { hours first-line STS }\end{array}$ & 133 & $\begin{array}{l}\text { Doxo: } 25.6 \text { TRB } \\
3 \text { hours: } 14.8 \\
\text { TRB } 24 \text { hours: } \\
7.6 \text { NS }\end{array}$ & - & $\begin{array}{l}\text { Doxo: } 5.5 \\
\text { TRB } 3 \text { hours: } 2.8 \\
\text { TRB } 24 \text { hours: } 3.1 \\
\text { NS }\end{array}$ & $\begin{array}{l}\text { TRB } 24 \text { hours vs doxo } \\
\text { HR } 0.94 \text { NS } \\
\text { TRB } 3 \text { hours vs } \\
\text { doxo HR I.30 NS } \\
\text { (preliminary analysis) }\end{array}$ \\
\hline 59 & II & $\begin{array}{l}\text { TRB } 1.5 \mathrm{mg} / \mathrm{m}^{2} 24 \mathrm{~h} \mathrm{q} 2 \mathrm{I} \\
\text { pretreated STS }\end{array}$ & 99 & 8 & - & 3.5 & 9.2 \\
\hline 62 & II & $\begin{array}{l}\text { TRB } 1.5 \mathrm{mg} / \mathrm{m}^{2} 24 \mathrm{~h} \mathrm{q} 1 \\
\text { pretreated STS }\end{array}$ & 36 & 8 & - & 1.7 & 12.1 \\
\hline 60 & II & $\begin{array}{l}\text { TRB } 1.5 \mathrm{mg} / \mathrm{m}^{2} 24 \mathrm{~h} \mathrm{q} 2 \mathrm{I} \\
\text { pretreated STS }\end{array}$ & 54 & 4 & - & 1.9 & 12.8 \\
\hline 61 & II & $\begin{array}{l}\text { TRB I.3-1.65 mg/m² } \\
\text { 3hq2I + dexamethasone } \\
\text { or placebo, pretreated } \\
\text { STS }\end{array}$ & 35 & 2.8 & - & 2.1 & 10.2 \\
\hline 51 & II & $\begin{array}{l}\text { TRB } 1.5 \mathrm{mg} / \mathrm{m}^{2} \\
\text { q3weeks vs TRB } 0.58 \\
\mathrm{mg} / \mathrm{m}^{2} 3 \text { hours day I, } \\
8,15 \text { every } 4 \text { weeks. } \\
\text { L-sarcoma, after failure } \\
\text { anthracyclines and } \\
\text { ifosfamide }\end{array}$ & 270 & 5.6 vs 1.6 & $\begin{array}{l}3.7 \text { vs } 2.3 \\
H R=0.73 \\
P=0.03\end{array}$ & $\begin{array}{l}3.3 \text { vs } 2.3, H R=0.76, \\
P=0.04\end{array}$ & $\begin{array}{l}\mid 3.9 \text { vs }|| \mid .8, H R=0.84 \text {, } \\
P=0.19\end{array}$ \\
\hline 63 & II & $\begin{array}{l}\text { TRB } 1.2 \mathrm{mg} / \mathrm{m}^{2} \mathrm{q} 3 \mathrm{wk} \\
\text { vs best supportive care } \\
\text { in translocation-related } \\
\text { sarcoma after standard } \\
\text { chemotherapy }\end{array}$ & 76 & 8 vs 0 & - & $\begin{array}{l}5.6 \text { vs } 0.9, \mathrm{HR}=0.07, \\
P<0.000 \mathrm{I}\end{array}$ & $\begin{array}{l}\text { Not reached vs } 8.0, \mathrm{HR} \\
=0.42, P=0.04\end{array}$ \\
\hline 68 & II & $\begin{array}{l}\text { TRB } 1.5 \mathrm{mg} / \mathrm{m}^{2} \mathrm{q} 2 \mathrm{Id} \\
\text { neoadjuvant myxoid } \\
\text { liposarcoma }\end{array}$ & 23 & 24 & 2 patients $\mathrm{pC}$ & & \\
\hline 58 & III & $\begin{array}{l}\text { TRB } 1.5 \mathrm{mg} / \mathrm{m}^{2} \mathrm{q} 21 \\
\text { vs doxorubicin in } \\
\text { translocation-related } \\
\text { sarcoma }\end{array}$ & 121 & $\begin{array}{l}5.9 \text { TRB vs } 27 \\
\text { doxo }\end{array}$ & - & HR 0.85 NS & $\begin{array}{l}\text { HR } 0.77 \text { NS } \\
\text { (preliminary analysis) }\end{array}$ \\
\hline 43 & $\begin{array}{l}\text { III } \\
\text { IA }\end{array}$ & $\begin{array}{l}\text { TRB } 1.5 \mathrm{mg} / \mathrm{m}^{2} \mathrm{q} 2 \mathrm{I} \\
\text { vs dacarbazin in } \\
\mathrm{L} \text {-sarcomas after } \\
\text { anthracycline and one } \\
\text { additional chemotherapy }\end{array}$ & 518 & 9.9 vs 6.9 & - & $\begin{array}{l}4.2 \text { vs } I .5, H R=0.52 \\
P<0.000 I\end{array}$ & $\begin{array}{l}I 2.9 \text { vs } 12.4, H R=0.87 \text {, } \\
P=0.37\end{array}$ \\
\hline 64 & $\mathrm{IV}^{\mathrm{a}}$ & $\begin{array}{l}\text { TRB } 1.5 \mathrm{mg} / \mathrm{m}^{2} \mathrm{q} 3 \mathrm{wk} . \\
\text { All STS after standard } \\
\text { chemotherapy }\end{array}$ & $\begin{array}{l}807 \text { evaluable } \\
\text { out of } I, 895 \\
476 / 807 \\
\text { L-sarcoma }\end{array}$ & $\begin{array}{l}\text { All } 5.9 \\
\text { L } 6.9\end{array}$ & 2.3 & - & $\begin{array}{l}\text { All II.9 } \\
\text { L-sarcoma } 16.2\end{array}$ \\
\hline
\end{tabular}

Note: a Worldwide expanded access program study.

Abbreviations: IA, interim analysis; L-sarcoma, liposarcoma and leiomyosarcoma; RR, response rate; TTP, time to progression; PFS, progression free survival; OS, overall survival; STS, soft tissue sarcoma; TRB, trabectedine; MTD, maximum tolerated dose; q, every; doxo, doxorubicin; HR, hazard ratio; NS, not significant; pCR, pathological complete response; NA, not applicable. 
response rates (5.6\%) and short median PFS (3.3 months) with a median OS of 13.9 months were found in the now regular dosing arm of $1.5 \mathrm{mg} / \mathrm{m}^{2}$ every 3 weeks. ${ }^{51}$

Recently, the results of a Phase III trial with trabectedin vs dacarbazine in patients with L-sarcomas progressive after anthracyclines and one other prior chemotherapy were reported. ${ }^{43} \mathrm{~A}$ total of 518 patients were enrolled and randomly assigned to either trabectedin $(n=345)$ or dacarbazine $(n=173)$. Median PFS for trabectedin vs dacarbazine was 4.2 vs 1.5 months, $\mathrm{HR}=0.55, P<0.001)$. In the predefined subanalyses, all subgroups benefited from trabectedin, although the benefit was not statistically significant in all these subgroups. The interim analysis of OS ( $64 \%$ censored) demonstrated a nonsignificant $13 \%$ reduction in risk of death in the trabectedin arm compared with dacarbazine (median OS for trabectedin vs dacarbazine, 12.4 vs 12.9 months, $\mathrm{HR}=0.87, P=0.37$ ).

In conclusion, only a modest difference in the efficacy of trabectedin in translocation-related sarcomas compared to unselected STS (also including translocation-related STS) has been observed (both in the first and subsequent lines of therapy). More convincing results for translocation-related sarcomas compared to unselected STS were found in the expanded access trial. ${ }^{64}$ In this trial, STS patients progressive after standard chemotherapy were treated with trabectedin $1.5 \mathrm{mg} / \mathrm{m}^{2}$ every 3 weeks. Four hundred and seventy six of the $807(59 \%)$ assessable patients had "liposarcoma and leiomyosarcoma (L-sarcomas)". The ORR of the total of 807 patients was $5.9 \%(95 \% \mathrm{CI}=4.4-7.8)$. For patients with L-sarcomas $(n=476)$, the ORR was 6.9\% (95\% CI =4.8-9.6), whereas patients classified as non-L-sarcoma $(n=302)$ had an ORR of $4.0 \%(95 \% \mathrm{CI}=2.1-6.8)$. A total of 258 patients with L-sarcoma experienced CR, PR, or stable disease, a clinical benefit rate of $54 \%$, compared with 114 patients with non-L-sarcoma (the clinical benefit rate of $38 \%$ ). Nine hundred and three patients were evaluable for OS. In the total group, median OS was 11.9 months; in the group of patients with L-sarcomas $(n=509)$ median OS was 16.2 months $(95 \%$ $\mathrm{CI}=14.1-19.5)$, and in the non-L-sarcoma patients median OS was 8.4 months $(95 \% \mathrm{CI}=7.1-10.7)$. Patients with liposarcoma ( $n=184)$ had a 2 months longer median survival than those with leiomyosarcoma ( $n=325 ; 18.1$ vs 16.2 months). ${ }^{64}$

\section{Combinations of trabectedin in STS}

The combination of trabectedin and doxorubicin has been studied in two Phase I trials and one Phase II trial (Table 3). ${ }^{65-}$

${ }^{67}$ Both Phase I studies in unselected STS patients concluded the recommended Phase II dose of doxorubicin as $60 \mathrm{mg} /$ $\mathrm{m}^{2}$ every 3 weeks. For trabectedin, the recommended dose in one study ${ }^{65}$ was $0.7 \mathrm{~g} / \mathrm{m}^{2}$ in 3 hours every 3 weeks, and in the other study $1.1 \mathrm{~g} / \mathrm{m}^{2}$ in 3 hours every 3 weeks. ${ }^{66}$ Dose-limiting toxicities were thrombocytopenia, (febrile) neutropenia, and asthenia. The difference in recommended trabectedin dose seems to be explained by the difference in accepted pretreatments. Patients in the study assessing the $0.7 \mathrm{~g} / \mathrm{m}^{2}$ dose $^{65}$ were heavily pretreated, while in the $1.1 \mathrm{~g} / \mathrm{m}^{2}$ study ${ }^{66}$ $0-1$ prior treatments were allowed and, therefore, only seven out 41 patients had received prior systemic therapy. Other more frequently occurring toxicities were increased ALT/ AST, nausea, vomiting, and stomatitis. The ORR in the two Phase I trials was $12 \%-17.9 \%$, which is numerically higher than the response rate of single-agent trabectedin but lower

Table 3 Combinations of trabectedin in STS patients

\begin{tabular}{|c|c|c|c|c|c|c|c|}
\hline Reference & Phase & Design & $\mathbf{n}$ & RR (\%) & $\begin{array}{l}\text { TTP } \\
\text { (months) }\end{array}$ & PFS (months) & OS (months) \\
\hline 69 & 1 & $\begin{array}{l}\text { TRB } 0.9 \mathrm{mg} / \mathrm{m}^{2} \mathrm{dl} \text { and } \\
\text { gemcitabine } 700 \mathrm{mg} / \mathrm{m}^{2} \\
\mathrm{dl}+8 \mathrm{q} 2 \mathrm{I} \text { days }\end{array}$ & $5 *$ & & & & \\
\hline 65 & I & $\begin{array}{l}\text { RD TRB } 0.7 \mathrm{mg} / \mathrm{m}^{2} \\
3 \text { hours and doxorubicin } \\
60 \mathrm{mg} / \mathrm{m}^{2} \mathrm{q} 2 \mathrm{l} \text {, pretreated STS } \\
\text { and breast cancer }\end{array}$ & 29 STS & 17.9 & 12.5 & NA & NA \\
\hline 66 & 1 & $\begin{array}{l}\text { MTD TRB I.I } \mathrm{mg} / \mathrm{m}^{2} 3 \text { hours } \\
\text { and doxorubicin } 60 \mathrm{mg} / \mathrm{m}^{2} \mathrm{q} 2 \mathrm{I} \\
\text { STS 0-I prior chemotherapy } \\
\text { other than anthracyclines }\end{array}$ & 41 & 12 & & 9.2 & Not reached, $>\mid 4.8$ \\
\hline 67 & II & $\begin{array}{l}\text { TRB I.I mg/m in } 3 \text { hours and } \\
\text { doxorubicin } 60 \mathrm{mg} / \mathrm{m}^{2} \text { q2 I day. } \\
\text { First line, } \mathrm{u}-\mathrm{LMS} \text {, and STS-LMS }\end{array}$ & 109 & $\begin{array}{l}\text { u-LMS } 59.6 \\
\text { STS-LMS } 39.4\end{array}$ & $\begin{array}{l}\text { u-LMS } 6.6 \\
\text { STS-LMS } \\
12.5\end{array}$ & $\begin{array}{l}\text { u-LMS } 8.2 \\
\text { STS-LMS } 12.9\end{array}$ & $\begin{array}{l}\text { u-LMS } 20.2 \\
\text { STS-LMS } 34.5 \\
\text { (median follow up } 9.9 \text { and } 14.5 \text { ) }\end{array}$ \\
\hline
\end{tabular}

Note: *Not tolerated; 4/5 patients DLT.

Abbreviations: u-LMS, uterine LMS; RD, recommended dose; MTD, maximum tolerated dose; TRB, trabectidin; LMS, leiomyosarcoma; STS, soft-tissue sarcoma; RR, response rate; TTP, time to progression; PFS, progression free survival; OS, overall survival ; DLT, dose limiting toxicity; q, every; NA, not applicable. 
than the response rate of single-agent doxorubicin when administered as first-line therapy.

In a French Phase II trial, previously untreated patients with advanced or metastatic uterine leiomyosaroma (u-LMS, $\mathrm{n}=47$ ) or soft-tissue leiomyosarcoma (STS-LMS, $\mathrm{n}=61$ ) were treated with doxorubicin $60 \mathrm{mg} / \mathrm{m}^{2}$ and trabectedin $1.1 \mathrm{~g} / \mathrm{m}^{2}$ in 3 hours every 3 weeks up to six cycles. ${ }^{67}$ High ORRs were found: $59.6 \%$ for $\mathrm{u}-\mathrm{LMS}$ and $39.4 \%$ for STS-LMS. The most common grade 3-4 treatment-associated adverse events were (febrile) neutropenia, thrombocytopenia, anemia, increased ALT, and fatigue.

The combination of doxorubicin and trabectedin seems promising. The high ORR suggests a potential role in a neoadjuvant setting. So far, only one study on single-agent trabectedin in the neoadjuvant setting for myxoid liposarcoma has been published, reporting a response rate of $24 \% .{ }^{68}$ Another point of interest would be the continuation of trabectedin after the six cycles of combined trabectedin and doxorubicin since a very recent study of Le Cesne et $\mathrm{al}^{55}$ found that continued trabectedin in patients with disease control after six cycles is superior to restarting treatment at progression.

The combination of trabectedin and gemcitabine has proven to be not tolerable. ${ }^{69} \mathrm{~A}$ phase $\mathrm{Ib}$ trial in pretreated STS patients treated with a combination of trabectedin and olaparib, a PARP inhibitor, is now open for recruitment (NCT02398058).

\section{Conclusion}

In conclusion, trabectedin has consistent activity in all types of STS. Trabectedin can be positioned after failure of first-line therapy with anthracyclines or in patients unfit for anthracycline-based therapy. There is no rationale to replace anthracycline-based first-line therapy with trabectedin currently, since trabectedin has not demonstrated a survival or response rate advantage over doxorubicin.

The combination of doxorubicin and trabectedin deserves further study as first-line palliative therapy as well as in the neoadjuvant setting. This is also the case for trabectedin maintenance therapy after induction therapy with six cycles of doxorubicin.

For second-line and further therapy, no preferred sequence suiting for all STS subtypes can be provided. The choice should be made on an individual basis, taking into account the histological subtype, aim of the treatment, and the expected toxicity. Unfortunately, almost no quality-oflife data are available for the different chemotherapeutical options. Future studies should include quality-of-life measurements.
Beyond first-line treatment, trabectedin has the advantage of a relatively favorable toxicity profile, but the disadvantage of the need of a central venous catheter and the 24 hours administration. Based on the expanded access program data, there is more rationale in translocation-related sarcomas for the use of trabectedin in terms of efficacy. In these sarcomas, it seems reasonable to place trabectedin as second-line treatment. In other sarcomas, several options can be considered including trabectedin.

Opportunities for the near future will be the investigation of maintenance therapy with trabectedin after doxorubicin induction therapy and combinations of trabectedin and doxorubicin.

\section{Disclosure}

WvdG received speaker's fee from Eli Lilly and Novartis and institutional research grants from Novartis and GSK. RJ has consulted for the following: Pharmamar, JJ, Adaptimmune, Eisai, Daichii Sankyo, Imclone/Lilly, Immodulon, Immunedesign, Merck, and Morphotek. The authors report no other conflicts of interest in this work.

\section{References}

1. Gatta G, van der Zwan JM, Casali PG, et al. Rare cancers are not so rare: the rare cancer burden in Europe. Eur J Cancer. 2011;47(17):2493-2511.

2. Clark MA, Fisher C, Judson I, Thomas JM. Soft-tissue sarcomas in adults. N Engl J Med. 2005;353(7):701-711.

3. Fletcher CD, Unni KK, Mertens F, editors. WHO Classification of Tumours of Soft Tissue and Bone. Lyon, France: IARC Press; 2013.

4. Smith SM, Coleman J, Bridge JA, Iwenofu OH. Molecular diagnostics in soft tissue sarcomas and gastrointestinal stromal tumors. J Surg Oncol. 2015;111(5):520-531.

5. Tucker MA, D’Angio GJ, Boice JD Jr, et al. Bone sarcomas linked to radiotherapy and chemotherapy in children. $N$ Engl J Med. 1987;317(10):588-593.

6. Rubino C, Shamsaldin A, Le MG, et al. Radiation dose and risk of soft tissue and bone sarcoma after breast cancer treatment. Breast Cancer Res Treat. 2005;89(3):277-288.

7. Young RJ, Brown NJ, Reed MW, Hughes D, Woll PJ. Angiosarcoma. Lancet Oncol. 2010;11(10):983-991.

8. Schulz TF, Cesarman E. Kaposi Sarcoma-associated Herpesvirus: mechanisms of oncogenesis. Curr Opin Virol. 2015;14:116-128.

9. Brems H, Beert E, de Ravel T, Legius E. Mechanisms in the pathogenesis of malignant tumours in neurofibromatosis type 1. Lancet Oncol. 2009;10(5):508-515.

10. Ryan CW, Desai J. The past, present, and future of cytotoxic chemotherapy and pathway-directed targeted agents for soft tissue sarcoma. Am Soc Clin Oncol Educ Book. 2013.

11. van der Graaf WT, Blay JY, Chawla SP, et al. Pazopanib for metastatic soft-tissue sarcoma (PALETTE): a randomised, double-blind, placebocontrolled phase 3 trial. Lancet. 2012;379(9829):1879-1886.

12. Linch M, Miah AB, Thway K, Judson IR, Benson C. Systemic treatment of soft-tissue sarcoma-gold standard and novel therapies. Nat Rev Clin Oncol. 2014;11(4):187-202.

13. Pang A, Carbini M, Maki RG. Contemporary therapy for advanced softtissue Sarcomas in adults: a review. JAMA Oncol. Epub May 5, 2016.

14. Bramwell VH, Anderson D, Charette ML. Doxorubicin-based chemotherapy for the palliative treatment of adult patients with locally advanced or metastatic soft tissue sarcoma. Cochrane Database Syst Rev. 2003;(3):CD003293. 
15. Judson I, Verweij J, Gelderblom H, et al. Doxorubicin alone versus intensified doxorubicin plus ifosfamide for first-line treatment of advanced or metastatic soft-tissue sarcoma: a randomised controlled phase 3 trial. Lancet Oncol. 2014;15(4):415-423.

16. Tap WD, Jones RL, Van Tine BA, et al. Olaratumab and doxorubicin versus doxorubicin alone for treatment of soft tissue sarcomas: an open label phase $1 \mathrm{~b}$ and randomised phase 2 trial. Lancet. 2016;388(10043):488-497.

17. Hensley ML, Blessing JA, Degeest K, Abulafia O, Rose PG, Homesley HD. Fixed-dose rate gemcitabine plus docetaxel as second-line therapy for metastatic uterine leiomyosarcoma: a Gynecologic Oncology Group phase II study. Gynecol Oncol. 2008;109(3):323-328.

18. Hensley ML, Blessing JA, Mannel R, Rose PG. Fixed-dose rate gemcitabine plus docetaxel as first-line therapy for metastatic uterine leiomyosarcoma: a Gynecologic Oncology Group phase II trial. Gynecol Oncol. 2008;109(3):329-334.

19. Pautier P, Floquet A, Penel N, et al. Randomized multicenter and stratified phase II study of gemcitabine alone versus gemcitabine and docetaxel in patients with metastatic or relapsed leiomyosarcomas: a Federation Nationale des Centres de Lutte Contre le Cancer (FNCLCC) French Sarcoma Group Study (TAXOGEM study). Oncologist. 2012;17(9):1213-1220.

20. Hensley ML, Miller A, O’Malley DM, et al. Randomized phase III trial of gemcitabine plus docetaxel plus bevacizumab or placebo as first-line treatment for metastatic uterine leiomyosarcoma: an NRG Oncology/Gynecologic Oncology Group study. J Clin Oncol. 2015;33(10):1180-1185

21. Seddon BM, Whelan J, Strauss JS, et al. A prospective randomised controlled phase III trial of gemcitabine and docetaxel compared with doxorubicin as first-line treatment in treatment in previously untreated advanced unresectable or metastatic soft tissue sarcomas. J Clin Oncol. 2015;33(Suppl):abstract 10500.

22. Casper ES, Waltzman RJ, Schwartz GK, et al. Phase II trial of paclitaxel in patients with soft-tissue sarcoma. Cancer Invest. 1998;16(7):442-446.

23. Penel N, Bui BN, Bay JO, et al. Phase II trial of weekly paclitaxel for unresectable angiosarcoma: the ANGIOTAX Study. J Clin Oncol. 2008;26(32):5269-5274.

24. Schlemmer M, Reichardt P, Verweij J, et al. Paclitaxel in patients with advanced angiosarcomas of soft tissue: a retrospective study of the EORTC soft tissue and bone sarcoma group. Eur J Cancer. 2008;44(16):2433-2436.

25. Fata F, O'Reilly E, Ilson D, et al. Paclitaxel in the treatment of patients with angiosarcoma of the scalp or face. Cancer. 1999;86(10):2034-2037.

26. Skubitz KM, Haddad PA. Paclitaxel and pegylated-liposomal doxorubicin are both active in angiosarcoma. Cancer. 2005;104(2):361-366.

27. Nagano T, Yamada Y, Ikeda T, Kanki H, Kamo T, Nishigori C. Docetaxel: a therapeutic option in the treatment of cutaneous angiosarcoma: report of 9 patients. Cancer. 2007;110(3):648-651.

28. Ray-Coquard IL, Domont J, Tresch-Bruneel E, et al. Paclitaxel given once per week with or without bevacizumab in patients with advanced angiosarcoma: a randomized Phase II trial. J Clin Oncol. 2015;33(25):2797-2802

29. Mir O, Domont J, Cioffi A, et al. Feasibility of metronomic oral cyclophosphamide plus prednisolone in elderly patients with inoperable or metastatic soft tissue sarcoma. Eur J Cancer. 2011;47(4):515-519.

30. Sharma S, Takyar S, Manson SC, Powell S, Penel N. Efficacy and safety of pharmacological interventions in second- or later-line treatment of patients with advanced soft tissue sarcoma: a systematic review. $B M C$ Cancer. 2013;13:385.

31. Tascilar M, Loos WJ, Seynaeve C, Verweij J, Sleijfer S. The pharmacologic basis of ifosfamide use in adult patients with advanced soft tissue sarcomas. Oncologist. 2007;12(11):1351-1360.

32. Lorigan P, Verweij J, Papai Z, et al. Phase III trial of two investigational schedules of ifosfamide compared with standard-dose doxorubicin in advanced or metastatic soft tissue sarcoma: a European organisation for research and treatment of cancer soft tissue and bone sarcoma group study. J Clin Oncol. 2007;25(21):3144-3150.
33. Sleijfer S, Ouali M, van Glabbeke M, et al. Prognostic and predictive factors for outcome to first-line ifosfamide-containing chemotherapy for adult patients with advanced soft tissue sarcomas: an exploratory, retrospective analysis on large series from the European organization for research and treatment of cancer-soft tissue and bone sarcoma group (EORTC-STBSG). Eur J Cancer 2010;46(1):72-83.

34. Martin-Liberal J, Alam S, Constantinidou A, et al. Clinical activity and tolerability of a 14-day infusional Ifosfamide schedule in soft-tissue sarcoma. Sarcoma. 2013;2013:868973.

35. Patel SR, Gandhi V, Jenkins J, et al. Phase II clinical investigation of gemcitabine in advanced soft tissue sarcomas and window evaluation of dose rate on gemcitabine triphosphate accumulation. J Clin Oncol. 2001;19(15):3483-3489.

36. Hartmann JT, Oechsle K, Huober J, et al. An open label, non-comparative phase II study of gemcitabine as salvage treatment for patients with pretreated adult type soft tissue sarcoma. Invest New Drugs. 2006;24(3):249-253.

37. Svancarova L, Blay JY, Judson IR, et al. Gemcitabine in advanced adult soft-tissue sarcomas. A phase II study of the EORTC Soft Tissue and Bone Sarcoma Group. Eur J Cancer. 2002;38(4):556-559.

38. Ferraresi V, Ciccarese M, Cercato MC, et al. Gemcitabine at fixed doserate in patients with advanced soft-tissue sarcomas: a mono-institutional phase II study. Cancer Chemother Pharmacol. 2008;63(1):149-155.

39. Maki RG, Wathen JK, Patel SR, et al. Randomized phase II study of gemcitabine and docetaxel compared with gemcitabine alone in patients with metastatic soft tissue sarcomas: results of sarcoma alliance for research through collaboration study 002 [corrected]. J Clin Oncol. 2007;25(19):2755-2763.

40. Buesa JM, Mouridsen HT, van Oosterom AT, et al. High-dose DTIC in advanced soft-tissue sarcomas in the adult. A phase II study of the E.O.R.T.C. Soft Tissue and Bone Sarcoma Group. Ann Oncol. 1991;2(4):307-309.

41. Garcia-Del-Muro X, Lopez-Pousa A, Maurel J, et al. Randomized phase II study comparing gemcitabine plus dacarbazine versus dacarbazine alone in patients with previously treated soft tissue sarcoma: a Spanish Group for Research on Sarcomas study. J Clin Oncol. 2011;29(18):2528-2533.

42. Losa R, Fra J, Lopez-Pousa A, et al. Phase II study with the combination of gemcitabine and DTIC in patients with advanced soft tissue sarcomas. Cancer Chemother Pharmacol. 2007;59(2):251-259.

43. Demetri GD, von Mehren M, Jones RL, et al. Efficacy and safety of trabectedin or dacarbazine for metastatic liposarcoma or leiomyosarcoma after failure of conventional chemotherapy: results of a Phase III randomized multicenter clinical trial. J Clin Oncol. 2016;34(8):786-793.

44. Schoffski P, Chawla S, Maki RG, et al. Eribulin versus dacarbazine in previously treated patients with advanced liposarcoma or leiomyosarcoma: a randomised, open-label, multicentre, phase 3 trial. Lancet. 2016;387(10028):1629-1637.

45. Cuevas C, Francesch A. Development of Yondelis (trabectedin, ET-743). A semisynthetic process solves the supply problem. Nat Prod Rep. 2009;26(3):322-337.

46. D'Incalci M, Badri N, Galmarini CM, Allavena P. Trabectedin, a drug acting on both cancer cells and the tumour microenvironment. $\mathrm{Br} J$ Cancer. 2014;111(4):646-650.

47. Larsen AK, Galmarini CM, D'Incalci M. Unique features of trabectedin mechanism of action. Cancer Chemother Pharmacol. 2016;77: 663-671.

48. Di Giandomenico S, Frapolli R, Bello E, et al. Mode of action of trabectedin in myxoid liposarcomas. Oncogene. 2014;33(44):5201-5210.

49. Grohar PJ, Griffin LB, Yeung C, et al. Ecteinascidin 743 interferes with the activity of EWS-FLI1 in Ewing sarcoma cells. Neoplasia. 2011;13(2):145-153.

50. Grohar PJ, Segars LE, Yeung C, et al. Dual targeting of EWS-FLI1 activity and the associated DNA damage response with trabectedin and SN38 synergistically inhibits Ewing sarcoma cell growth. Clin Cancer Res. 2014;20(5):1190-1203. 
51. Demetri GD, Chawla SP, von Mehren M, et al. Efficacy and safety of trabectedin in patients with advanced or metastatic liposarcoma or leiomyosarcoma after failure of prior anthracyclines and ifosfamide: results of a randomized phase II study of two different schedules. J Clin Oncol. 2009;27(25):4188-4196.

52. Bui-Nguyen B, Butrynski JE, Penel N, et al. A phase IIb multicentre study comparing the efficacy of trabectedin to doxorubicin in patients with advanced or metastatic untreated soft tissue sarcoma: the TRUSTS trial. Eur J Cancer. 2015;51(10):1312-1320.

53. Forouzesh B, Hidalgo M, Chu Q, et al. Phase I and pharmacokinetic study of trabectedin as a 1- or 3-hour infusion weekly in patients with advanced solid malignancies. Clin Cancer Res. 2009;15(10):3591-3599.

54. Summary of product characteristics Trabectedin. Available from: http:// www.ema.europa.eu/docs/en_GB/document_library/EPAR_-_Product_Information/human/000773/WC500045832.pdf. Accessed July 25, 2016.

55. Le Cesne A, Blay JY, Domont J, et al. Interruption versus continuation of trabectedin in patients with soft-tissue sarcoma (T-DIS): a randomised phase 2 trial. Lancet Oncol. 2015;16(3):312-319.

56. Garcia-Carbonero R, Supko JG, Maki RG, et al. Ecteinascidin-743 (ET-743) for chemotherapy-naive patients with advanced soft tissue sarcomas: multicenter phase II and pharmacokinetic study. J Clin Oncol. 2005;23(24):5484-5492.

57. Monk BJ, Blessing JA, Street DG, Muller CY, Burke JJ, Hensley ML A phase II evaluation of trabectedin in the treatment of advanced, persistent, or recurrent uterine leiomyosarcoma: a gynecologic oncology group study. Gynecol Oncol. 2012;124(1):48-52.

58. Blay JY, Leahy MG, Nguyen BB, et al. Randomised phase III trial of trabectedin versus doxorubicin-based chemotherapy as first-line therapy in translocation-related sarcomas. Eur J Cancer. 2014;50(6):1137-1147.

59. Le Cesne A, Blay JY, Judson I, et al. Phase II study of ET-743 in advanced soft tissue sarcomas: a European organisation for the research and treatment of cancer (EORTC) soft tissue and bone sarcoma group trial. J Clin Oncol. 2005;23(3):576-584.

60. Yovine A, Riofrio M, Blay JY, et al. Phase II study of ecteinascidin-743 in advanced pretreated soft tissue sarcoma patients. J Clin Oncol. 2004;22(5):890-899.
61. Paz-Ares L, Lopez-Pousa A, Poveda A, et al. Trabectedin in pre-treated patients with advanced or metastatic soft tissue sarcoma: a phase II study evaluating co-treatment with dexamethasone. Invest New Drugs. 2012;30(2):729-740.

62. Garcia-Carbonero R, Supko JG, Manola J, et al. Phase II and pharmacokinetic study of ecteinascidin 743 in patients with progressive sarcomas of soft tissues refractory to chemotherapy. J Clin Oncol. 2004;22(8):1480-1490.

63. Kawai A, Araki N, Sugiura H, et al. Trabectedin monotherapy after standard chemotherapy versus best supportive care in patients with advanced, translocation-related sarcoma: a randomised, open-label, phase 2 study. Lancet Oncol. 2015;16(4):406-416.

64. Samuels BL, Chawla S, Patel S, et al. Clinical outcomes and safety with trabectedin therapy in patients with advanced soft tissue sarcomas following failure of prior chemotherapy: results of a worldwide expanded access program study. Ann Oncol. 2013;24(6):1703-1709.

65. Sessa C, Perotti A, Noberasco C, et al. Phase I clinical and pharmacokinetic study of trabectedin and doxorubicin in advanced soft tissue sarcoma and breast cancer. Eur J Cancer. 2009;45(7):1153-1161.

66. Blay JY, von Mehren M, Samuels BL, et al. Phase I combination study of trabectedin and doxorubicin in patients with soft-tissue sarcoma. Clin Cancer Res. 2008;14(20):6656-6662.

67. Pautier P, Floquet A, Chevreau C, et al. Trabectedin in combination with doxorubicin for first-line treatment of advanced uterine or soft-tissue leiomyosarcoma (LMS-02): a non-randomised, multicentre, phase 2 trial. Lancet Oncol. 2015;16(4):457-464.

68. Gronchi A, Bui BN, Bonvalot S, et al. Phase II clinical trial of neoadjuvant trabectedin in patients with advanced localized myxoid liposarcoma. Ann Oncol. 2012;23(3):771-776.

69. Kasper B, Reichardt P, Pink D, et al. Combination of trabectedin and gemcitabine for advanced soft tissue sarcomas: results of a phase I dose escalating trial of the German Interdisciplinary Sarcoma Group (GISG). Mar Drugs. 2015;13(1):379-388.

70. Ueda T, Kakunaga S, Ando M, et al. Phase I and pharmacokinetic study of trabectedin, a DNA minor groove binder, administered as a 24-hour continuous infusion in Japanese patients with soft tissue sarcoma. Invest New Drugs. 2014;32(4):691-699.
Cancer Management and Research

\section{Publish your work in this journal}

Cancer Management and Research is an international, peer-reviewed open access journal focusing on cancer research and the optimal use of preventative and integrated treatment interventions to achieve improved outcomes, enhanced survival and quality of life for the cancer patient. The manuscript management system is completely online and includes

\section{Dovepress}

a very quick and fair peer-review system, which is all easy to use. Visit $\mathrm{http}: / /$ www.dovepress.com/testimonials.php to read real quotes from published authors. 